\title{
Bulk metallic glass matrix composites
}

\author{
H. Choi-Yima) and W. L. Johnson \\ W. M. Keck Laboratory of Engineering Materials, Mail Code 138-78, California Institute of Technology, \\ Pasadena, California 91125
}

(Received 22 September 1997; accepted for publication 28 October 1997)

\begin{abstract}
Composites with a bulk metallic glass matrix were synthesized and characterized. This was made possible by the recent development of bulk metallic glasses that exhibit high resistance to crystallization in the undercooled liquid state. In this letter, experimental methods for processing metallic glass composites are introduced. Three different bulk metallic glass forming alloys were used as the matrix materials. Both ceramics and metals were introduced as reinforcement into the metallic glass. The metallic glass matrix remained amorphous after adding up to a $30 \mathrm{vol} \%$ fraction of particles or short wires. X-ray diffraction patterns of the composites show only peaks from the second phase particles superimposed on the broad diffuse maxima from the amorphous phase. Optical micrographs reveal uniformly distributed particles in the matrix. The glass transition of the amorphous matrix and the crystallization behavior of the composites were studied by calorimetric methods. (C) 1997 American Institute of Physics. [S0003-6951(97)02852-0]
\end{abstract}

Recently there has been considerable scientific and industrial interest in a variety of metal matrix composites as a way to improve mechanical properties compared to unreinforced alloys. ${ }^{1-3}$ Those materials are made by reinforcing alloys with long or short fibers, whiskers, or particles. Continuously reinforced composites provide maximum strength and stiffness in one direction but are anisotropic. ${ }^{4}$ Discontinuously reinforced metal matrix composites have been demonstrated to offer essentially isotropic properties with substantial improvements in strength and stiffness relative to those available with unreinforced materials. ${ }^{5,6}$ Particulate composites have the further advantages of being machinable and workable using many conventional processing techniques. Many metals and ceramics have been considered as possible matrix materials. The most studied metal matrix for application at temperatures below $450{ }^{\circ} \mathrm{C}$ is aluminum. ${ }^{7} \mathrm{Ti}-$ tanium has been extensively studied from the perspective of higher-temperature applications. ${ }^{8}$ In this work, bulk metallic glasses were used as matrices reinforced with refractory ceramics, ductile metal particles, or short wires. This was made possible by the use of recently reported multicomponent alloys that exhibit an extremely high glass forming ability, e.g., $\mathrm{La}-\mathrm{Al}-\mathrm{Ni},{ }^{9} \mathrm{Zr}-\mathrm{Al}-\mathrm{Cu}-\mathrm{Ni},{ }^{10}$ and $\mathrm{Zr}-\mathrm{Ti}-\mathrm{Cu}-\mathrm{Ni}-\mathrm{Be} .{ }^{11}$ In the work described here, $\mathrm{Zr}-\mathrm{Ti}-\mathrm{Cu}-\mathrm{Ni}$ (Ref. 12) and $\mathrm{Zr}-\mathrm{Ti}(\mathrm{Nb})-\mathrm{Al}-\mathrm{Cu}-\mathrm{Ni}$ (Ref. 13) alloys, which show extraordinary glass forming ability, were used as the matrix. These bulk metallic glasses have promising properties such as high yield strength and a high elastic strain limit combined with relatively high fracture toughness, fatigue, and corrosion resistance. ${ }^{14-17}$ However, they have little ductility in tension. This lack of tensile ductility could be an important drawback in many applications. Thus, one of the motivations for adding second phase particles to the metallic glass was to hinder propagation of shear bands and encourage the formation of multiple shear bands. In this letter, we will focus on the processing of particulate reinforced composites with a metallic glass matrix. More particularly, we

${ }^{a}$ Electronic mail: hchoi@cco.caltech.edu focus on one set of results obtained for WC particulate additions to a bulk metallic glass forming matrix. Other results are briefly summarized and will be described in more detail in a future publication.

In this work, we used three different compositions of bulk metallic glasses developed by Lin and Johnson ${ }^{12,13}$ as matrix materials. The nominal compositions of the three alloys are $\mathrm{Cu}_{47} \mathrm{Ti}_{34} \mathrm{Zr}_{11} \mathrm{Ni}_{8}$ (vitreous alloy 101 or $\mathrm{V} 101$ ), $\mathrm{Zr}_{52.5} \mathrm{Ti}_{5} \mathrm{Al}_{10} \mathrm{Cu}_{17.9} \mathrm{Ni}_{14.6}(\mathrm{~V} 105)$, and $\mathrm{Zr}_{57} \mathrm{Nb}_{5} \mathrm{Al}_{10} \mathrm{Cu}_{15.4} \mathrm{Ni}_{12.6}$ (V106). Ingots of alloys were prepared by arc melting a mixture of the elements having purity of $99.7 \%$ or better. A mixture of the pre-alloyed metallic glass forming elements and second phase material was combined by induction melting the glass forming alloy together with the solid second phase material on a water-cooled copper boat under a Tigettered argon atmosphere. Ceramics such as $\mathrm{SiC}$, WC, or $\mathrm{TiC}$, and the metals $\mathrm{W}$ or Ta were used as second phase materials. Volume fractions of particles ranged from 5\%$30 \%$ and the sizes of the particles varied between 20 and 80 $\mu \mathrm{m}$. Short (aspect ratio $=3$ ) tungsten wires with diameters of $100 \mu \mathrm{m}$ were also used in volume fractions of $10 \%$. The composite ingots were then remelted at temperatures ranging from 850 to $1100{ }^{\circ} \mathrm{C}$ under vacuum in a quartz tube using an induction heating coil and then injected through a nozzle into a copper mold using high purity argon at $1 \mathrm{~atm}$ pressure. The copper mold has internal rod shaped cavities $3 \mathrm{~cm}$ in length and $3 \mathrm{~mm}$ in diameter and strip shaped cavities $3 \mathrm{~cm}$ in length, $6 \mathrm{~mm}$ in width, and $2 \mathrm{~mm}$ in thickness. Cross sections of cast strips and rods were examined by $x$-ray diffraction. The glass transition temperature of the amorphous matrix and the crystallization behavior of composites were determined using differential scanning calorimetry (DSC) (Perkin-Elmer DSC 7).

The x-ray diffraction pattern in Fig. 1 was taken on a cross sectioned specimen containing $15 \mathrm{vol} \% \mathrm{WC}$ in a V106 matrix and shows diffraction peaks from WC particles superimposed on the broad diffuse scattering maxima from the amorphous phase. No other phases are detected within the sensitivity limits of $x$-ray diffraction. This implies that the presence of WC during processing did not adversely affect 


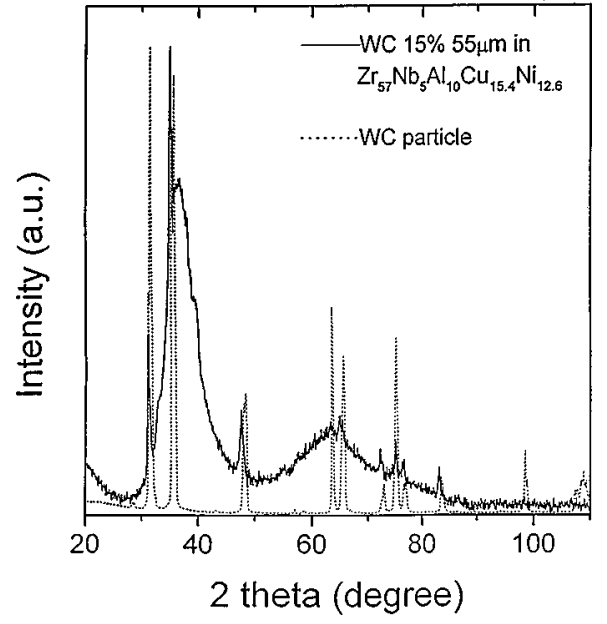

FIG. 1. X-ray diffraction pattern of the 15\% WC reinforced V106 matrix. The solid line is the diffraction pattern from the composite and the dotted line is the diffraction pattern from WC particles.

the glass forming ability of the matrix. An optical micrograph, depicted in Fig. 2, shows uniformly distributed WC particles in the metallic glass matrix. In this case, the volume fraction of WC particles was $10 \%$.

Figure 3 shows DSC scans of the pure amorphous alloy V106 and a series of WC reinforced composites for V106 using a heating rate of $10 \mathrm{~K} / \mathrm{m}$. The mean size of the WC particles was $50 \mu \mathrm{m}$. The scans exhibit an endothermic heat event characteristic of the glass transition followed by two distinguishably characteristic exothermic events. The exothermic events indicate the successive stepwise transformation from a metastable glassy state to a mixture of two or more equilibrium crystalline phases following heating. The glass transition temperature, $T_{g}$, is defined here as the onset of the endothermic DSC event. The crystallization temperature, $T_{x}$, is defined as the onset temperature of the first exothermic event. Based on the DSC scans, it is observed that the addition of particulate WC into the V106 produces no discernible change in either $T_{g}$ or $T_{x}$ and, within the sensitivity of the technique, this holds regardless of the WC volume fraction.

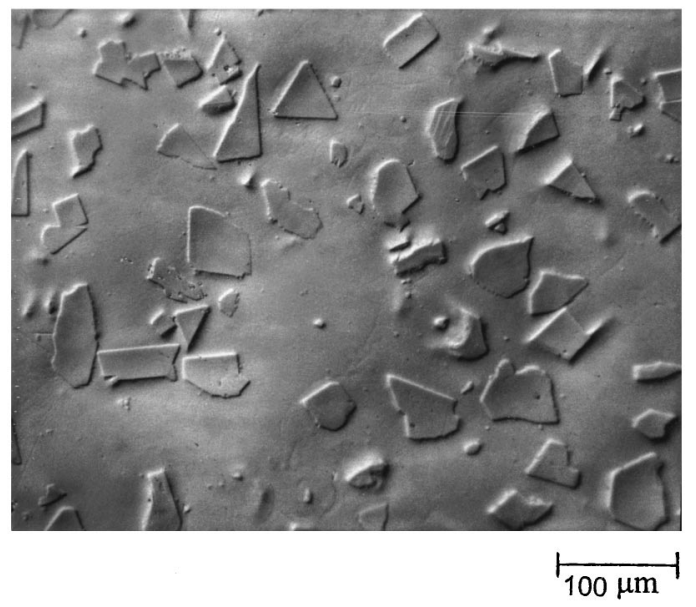

FIG. 2. An optical micrograph showing uniformly distributed WC particles in the V106 matrix. The size of particles is about $50 \mu \mathrm{m}$. The volume fraction of WC is $10 \%$.

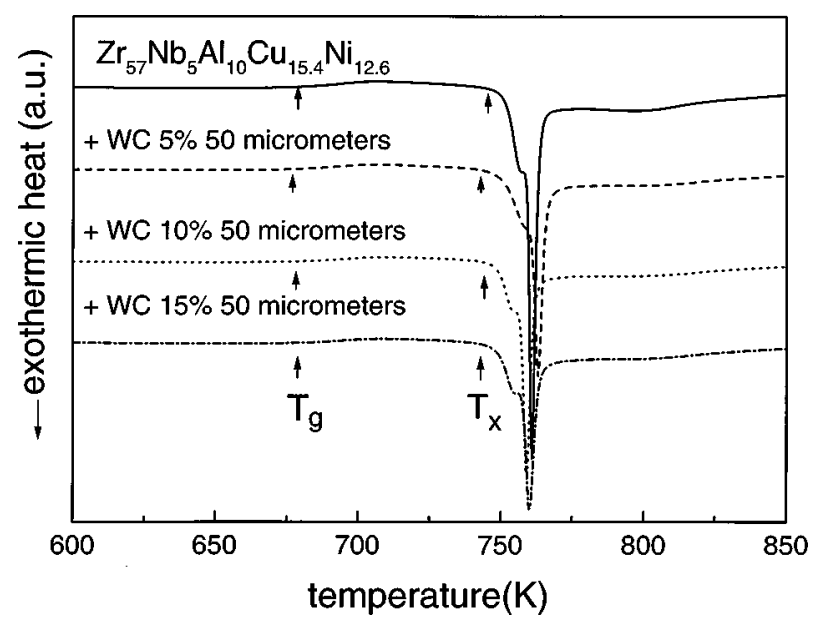

FIG. 3. DSC thermogram (heating rate of $10 \mathrm{~K} / \mathrm{m}$ ) of $\mathrm{V} 106$ and $\mathrm{WC}$ reinforced V106. $T_{g}$ is the onset of the glass transition temperature and $T_{x}$ is the onset temperature of the crystallization event.

The results discussed above apply to WC reinforced V106. In addition to WC, metallic glasses composites were made with $\mathrm{SiC}, \mathrm{TiC}, \mathrm{W}$, and $\mathrm{Ta}$ reinforcements. Table I gives an overview of the various combinations of metallic glasses and reinforcements which have been processed and characterized. "A" stands for an amorphous matrix after processing; " $\mathrm{X}$ " stands for a fully or partially crystallized matrix after processing. The diameter of short wires is 100 $\mu \mathrm{m}$ and the aspect ratio is 3 . All specimens are $3 \mathrm{~mm}$ diameter rods. From Table I we can conclude that many metallic glass/reinforcement mixtures used in this work are very stable with respect to nucleation and growth of second phases under the processing conditions used here.

This success in making composites with an amorphous matrix was unexpected. According to early studies of crystal nucleation, such second phase crystalline solid additions to the glass forming melts should tend to act as catalytic sites for heterogeneous crystal nucleation and growth. ${ }^{18}$ The absence of heterogeneous nucleation of crystalline phases in the metallic glass induced by interfacial contact with the re-

TABLE I. Lists of combinations among three different compositions of bulk metallic glasses and particles. V101 is $\mathrm{Cu}_{47} \mathrm{Ti}_{34} \mathrm{Zr}_{11} \mathrm{Ni}_{8}$. V105 is $\mathrm{Zr}_{52.5} \mathrm{Ti}_{5} \mathrm{Al}_{10} \mathrm{Cu}_{17.9} \mathrm{Ni}_{14.6}$. V106 is $\mathrm{Zr}_{57} \mathrm{Nb}_{5} \mathrm{Al}_{10} \mathrm{Cu}_{15.4} \mathrm{Ni}_{12.6}$.

\begin{tabular}{lccc}
\hline \hline Reinforcement/matrix & V101 & V105 & V106 \\
\hline SiC $10 \%, 80 \mu \mathrm{m}$ & $\mathrm{A}$ & $\mathrm{A}$ & $\mathrm{A}$ \\
$\mathrm{SiC} 20 \%, 80 \mu \mathrm{m}$ & $\mathrm{A}$ & $\mathrm{A}$ & $\mathrm{A}$ \\
$\mathrm{SiC} 30 \%, 80 \mu \mathrm{m}$ & $\mathrm{A}$ & $\mathrm{X}$ & $\mathrm{X}$ \\
$\mathrm{SiC} 10 \%, 37 \mu \mathrm{m}$ & $\mathrm{A}$ & $\mathrm{X}$ & $\mathrm{A}$ \\
$\mathrm{SiC} 20 \%, 37 \mu \mathrm{m}$ & $\mathrm{A}$ & $\mathrm{X}$ & $\mathrm{X}$ \\
$\mathrm{SiC} 10 \%, 1 \mu \mathrm{m}$ & $\mathrm{X}$ & $\cdots$ & $\cdots$ \\
$\mathrm{TiC} 10 \%, 20 \mu \mathrm{m}$ & $\mathrm{A}$ & $\mathrm{X}$ & $\mathrm{A}$ \\
$\mathrm{WC} 5 \%, 50 \mu \mathrm{m}$ & $\mathrm{X}$ & $\mathrm{A}$ & $\mathrm{A}$ \\
$\mathrm{WC} 10 \%, 50 \mu \mathrm{m}$ & $\mathrm{X}$ & $\mathrm{X}$ & $\mathrm{A}$ \\
$\mathrm{WC} 15 \%, 50 \mu \mathrm{m}$ & $\mathrm{X}$ & $\mathrm{X}$ & $\mathrm{A}$ \\
$\mathrm{W} 5 \%, 30 \mu \mathrm{m}$ & $\mathrm{A}$ & $\mathrm{A}$ & $\mathrm{A}$ \\
$\mathrm{W} 10 \%, 30 \mu \mathrm{m}$ & $\mathrm{X}$ & $\mathrm{X}$ & $\mathrm{A}$ \\
$\mathrm{W} 15 \%, 30 \mu \mathrm{m}$ & $\mathrm{X}$ & $\mathrm{X}$ & $\mathrm{A}$ \\
$\mathrm{W} 5 \%, 12 \mu \mathrm{m}$ & $\cdots$ & $\cdots$ & $\mathrm{A}$ \\
$\mathrm{Ta} 5 \%, 30 \mu \mathrm{m}$ & $\cdots$ & $\cdots$ & $\mathrm{A}$ \\
$\mathrm{Ta} 10 \%, 30 \mu \mathrm{m}$ & $\cdots$ & $\cdots$ & $\mathrm{A}$ \\
$\mathrm{W}$ short wire $10 \%$ & $\mathrm{~A}$ & $\mathrm{~A}$ & $\mathrm{~A}$ \\
\hline \hline
\end{tabular}


inforcement is related to crystallization kinetics in these glass forming melts. It has been shown, for example, that crystallization in these glasses is sluggish as evidenced by critical cooling rates of the order of $10-100 \mathrm{~K} / \mathrm{s}^{9-13}$

There are several reasons that the present bulk metallic glasses were chosen as a composite matrix. The bulk metallic glass forming alloys have a relatively low melting temperature. Therefore, chemical interactions between the reinforcement particles and the glass are relatively slow. This makes for easy control of interfacial reactions. Also, the low glass transition temperature decreases differential thermal stresses which arise between the reinforcement and the matrix during freezing and cooling. The synthesis methods used in this work are effective and simple. Particles were introduced directly into the metallic glass during induction melting. This method has the advantage of mixing the particles and glass forming liquid through rf stirring of the melt. Wetting of particles by the molten metal is observed to occur spontaneously. We found from this study that although V105 is the best glass former among the three alloys reported on in this letter (as assessed by earlier studies of critical cooling rates $^{12,13}$ ), V106 is the most processable matrix phase for fabricating composites containing a completely glassy matrix. The reduced glass transition temperature $\left(t_{g}\right)$, the ratio of the glass transition temperature, and the liquidus temperature of the crystalline alloy have often been cited as critical parameters determining the glass forming ability of metallic alloys. High values of $t_{g}$ are associated with good glass forming ability. According to Refs. 12 and 13, we know that the $t_{g}$ of V105 is 0.638 while the $t_{g}$ of V106 is 0.620 .

The maximum volume fraction of particles which could be introduced into the glassy alloys by the present casting methods was $30 \%$. A high speed of injecting molten alloys into the mold is necessary to achieve a high enough cooling rate to avoid crystallization of the matrix during casting. Adding a higher volume fraction of solid particles to the liquid alloy increases the viscosity of the mixture and lowers the injection speed achievable during casting, thus limiting the volume fraction of particles that can be added to the glass matrix. Table I also shows processability versus particle sizes. A given volume fraction of small particles has more interfacial area between the particles and glass forming alloy than the same volume fraction of larger particles. This enhances chemical reaction between the particles and the glass matrix. Dissolution or reaction of an excessive amount of the reinforcement phase with the metallic glass matrix changes the composition of the metallic glass in a manner which removes the composition from the optimum glass forming range. Interfacial reactions and dissolution of reinforcement into the melt are ultimately believed responsible for degradation of the glass forming ability of the matrix. These factors are discussed in more detail in a separate publication.

According to the present study, it has been proven that adding second phase crystalline materials into bulk metallic glass forming melt does not significantly degrade the bulk glass forming ability of the matrix alloy. The recent development of extremely stable bulk metallic glasses has made it possible to fabricate such composites. A variety of reinforcement materials has been added to the metallic glass matrix without inducing crystallization. The casting method used to synthesize the composites described in this letter has been proven simple and effective. Use of induction melting and the accompanying rf stirring has been found to be an efficient means of producing a uniform dispersion of reinforcement particles in the metallic glass matrix. Utilization of a relatively low maximum processing temperature prevents excessive reaction between the particles and the glass matrix, thus allowing one to retain the excellent glass forming ability of the matrix.

The authors would like to thank U. Köster, R. Busch, R. B. Dandliker, and R. D. Conner for valuable discussions. This work was jointly supported by the U.S. Army Research Office and the U.S. Air Force Office of Scientific Research under ARO Grant No. DAAH04-95-1-0233.

${ }^{1}$ I. A. Ibrahim, F. A. Mohamed, and E. J. Lavernia, J. Mater. Sci. 26, 1137 (1991).

${ }^{2}$ T. Christman, A. Needleman, and S. Suresh, Acta Metall. 37, 3029 (1989).

${ }^{3}$ M. F. Ashby, F. J. Blunt, and M. Bannister, Acta Metall. 37, 1847 (1989).

${ }^{4}$ A. K. Dhingra, J. Met. 38, 17 (1986).

${ }^{5}$ A. P. Divecha, S. G. Fishman, and S. D. Karmarkar, J. Met. 33, 12 (1981).

${ }^{6}$ R. J. Arsenault, Mater. Sci. Eng. 64, 171 (1984).

${ }^{7}$ J. C. Viala and J. Bouix, Mater. Chem. Phys. 11, 101 (1984).

${ }^{8}$ A. G. Metcalfe, in Metallic Matrix Composites, edited by K. C. Kreider (Academic, New York, 1974) p. 269.

${ }^{9}$ A. Inoue, T. Zhang, and T. Masumoto, Mater. Trans. JIM 31, 425 (1990).

${ }^{10}$ T. Zhang, A. Inoue, and T. Masumoto, Mater. Trans. JIM 32, 1005 (1991).

${ }^{11}$ A. Peker and W. L. Johnson, Appl. Phys. Lett. 63, 2342 (1993).

${ }^{12}$ X. H. Lin and W. L. Johnson, J. Appl. Phys. 78, 6514 (1995).

${ }^{13}$ X. H. Lin, Ph.D. thesis, X. H. Lin, and W. L. Johnson, Mater. Trans. JIM 38, 473 (1997).

${ }^{14}$ H. A. Bruck, T. Christman, A. J. Rosakis, and W. L. Johnson, Scr. Metall. Mater. 30, 429 (1994)

${ }^{15}$ H. A. Bruck, A. J. Rosakis, and W. L. Johnson, J. Mater. Res. 11, 503 (1996).

${ }^{16}$ C. G. Gilbert, R. O. Ritchie, and W. L. Johnson, Appl. Phys. Lett. 71, 476 (1997).

${ }^{17}$ D. Conner, A. J. Rosakis, and W. L. Johnson, Scr. Metall. Mater. (in press).

${ }^{18}$ D. Turnbull, Contemp. Phys. 10, 473 (1969). 